\title{
LA GOBERNANZA Y BUENA ADMINISTRACIÓN EN EL CONTEXTO DEL CONTROL DE LA INACTIVIDAD ADMINISTRATIVA
}

\author{
Governance and good administration in the context \\ of thecontrol of administrative inactivity
}

Diana Olvera Robles ${ }^{*}$

Alina del Carmen NETTEL BARRERA ${ }^{* *}$

Gabriela AgUAdo ROMERo

\begin{abstract}
Sumario:
I. Introducción II. Las transformaciones de la gestión pública y el Derecho administrativo III. Legalidad y gobernanza frente a la inactividad de la Administración IV. La protección de los derechos humanos vulnerados por la inactividad administrativaV. Conclusiones
\end{abstract}

Resumen: La gobernanza, desde la doble vertiente política y jurídica, presupone parámetros de actuación administrativa que fortalece las relaciones público privadas para la protección del interés general y la atención de las necesidades de los ciudadanos, todo ello, en el marco del Estado de Derecho y la protección de los derechos humanos. En esta dinámica, la inactividad administrativa frente a deberes de actuación normativos debe ser atendida bajo nuevos estándares legislativos coherentes con una buena administración.

Palabras clave: Gobernanza, buena administración, inactividad administrativa, principio de legalidad, Estado de Derecho

Abstract: Governance, from the dual aspect, political and legal, presupposes parameters administrative action that strengthens the private public relations for the protection of the general interest and attention to the necessities of citizens, all within the framework of the rule of law and the protection of Human Rights. In this dynamic, the administrative inactivity in front of normative duties of action will be addressed under new legislative standards coherents with a good administration.

Keywords: Governance, good administration, administrative inactivity, principle of legality, rule of law

\section{Introducción}

El concepto de gobernanza define nuevos estándares por parte de la administración pública. Dicha acepción comprende no sólo la forma en que es elegido un gobierno, sino también como

*Estudiante de Maestría en Ciencias Jurídicas en la Universidad Autónoma de Querétaro. Contacto: dianaolverarobles@gmail.com

** Doctoras son profesoras de tiempo completo en la Facultad de Derecho de la Universidad Autónoma de Querétaro. Son integrantes del Cuerpo Académico Consolidado “Derechos Humanos y Globalización”. Además pertenecen al Sistema Nacional de Investigadores como Candidato. Correos de contacto: alinanettel@hotmail.com y aguadogabriela@hotmail.com. 
éste lleva a cabo sus funciones desde una perspectiva organizacional y jurídica. Implica la gestión de los intereses públicos a través de instituciones y procesos transparentes y eficaces, lo que a su vez encuentra representación en procedimientos administrativos. En este sentido el trabajo que se propone a continuación aborda la gobernanza desde una perspectiva de análisis jurídico pues, más allá del ámbito político o económico, la gobernanza permea en la forma que concebimos la actuación administrativa sujeta a mandatos legales. Su objetivo se centra en abordar la importancia del procedimiento administrativo y el estudio de la inactividad como mecanismos de gestión coherentes con la buena administración, expresión jurídica de la gobernanza. Para conseguir este objetivo en el trabajo de investigación se utilizó un modelo metodológico dogmático-formalista para el análisis, interpretación y sistematización de la norma, la doctrina y la jurisprudencia. Asimismo, se aplicó un método deductivo que parte de las premisas más generales en relación con la concepción de la gobernanza para analizar los aspectos más específicos de esta forma de gestión pública relacionada con la actuación de las administraciones públicas. Las fuentes de información en este trabajo de investigación han sido la legislación, la jurisprudencia y la doctrina así como otros documentos de estudio emitidos por los organismos internacionales.

\section{Las transformaciones de la gestión pública y el derecho administrativo}

La ciencia de la administración y el derecho administrativo son dos disciplinas científicas independientes que encuentran, en el ámbito de su interés a las administraciones públicas ${ }^{1}$. Tradicionalmente, los estudios del derecho administrativo abordan el régimen jurídico de la actuación administrativa y sólo de manera accesoria abordan temas de eficiencia o eficacia administrativa en relación con las reglas que recoge el ordenamiento. Por su parte, la ciencia de la administración atiende de manera directa las formas de gestión de las organizaciones públicas por lo que evoluciona rápidamente al no tener de intermediario la acción del legislador que construye el ordenamiento. El derecho administrativo, en este sentido, se transforma paulatinamente en la medida que se van adscribiendo al derecho mecanismos específicos de actuación ${ }^{2}$. Estos mecanismos responden a formas de gestión que se movilizan entre la doctrina y cruzan la frontera de los países. En las últimas décadas, la globalización económica y jurídica ${ }^{3}$ han permeado en la mayoría de los países de occidente y esto provoca una homogeneización de la forma de gestión administrativa.

Las formas de gestión que han adquirido mayor relevancia en las últimas décadas tras un modelo burocrático o paternalista es el managment y el new public managment ${ }^{4}$, justo antes de la incursión de la gobernanza. La transformación atiende a la desburocratización de la gestión aplicando técnicas propias del ámbito gerencial privado. La eficacia se instituye como un parámetro de evaluación del desempeño. En este sentido se puede observar cómo se evita la

1 Arenilla, Manuel (coord. 2010), “Administración pública y ciencia de la administración”, en: La administración pública entre dos siglos: (Ciencia de la Administración, Ciencia Política y Derecho Administrativo): Homenaje a Mariano Baena del Alcázar, España, INAP, pp. 39-68.105.

2 En este sentido coexisten dos realidades en torno al fenómeno, por una parte la aplicación burocrática de la norma bajo el principio de legalidad estricta y por la otra el desarrollo organizacional operado bajo el principio de eficacia. Nieto García, Alejandro (2008), El desgobierno de lo público, Barcelona, Ariel,p. 268.

3 El derecho se ha transformado como consecuencia de la desespacialización de las relaciones económicas que deben ser atendidas para la resolución de conflictos, de ahí que se habla de la globalización jurídica. AuBY, JeanBernard (2001) “Globalización y descentralización”, Revista de Administración Pública, No. 156, INAP, Madrid, p. 8.

4 García Sánchez, Isabel (2007), La nueva gerencia pública: evolución y tendencias, Presupuesto y gasto público, España, Vol. 47, p.14. 
asimilación del Estado omnicomprensivo y procurador pasando a la idealización de un Estado que se sujeta a estándares de actuación justificados al cumplimiento de determinados fines gerenciales 5 .

La gestión en el ámbito público y el privado tienen objetivos distintos, en el primero, la atención del interés general es prioritario, en el segundo, el lucro, es el legítimo aliciente de las políticas y reglas que se adoptan. Desde el ámbito público, el estudio de principios de actuación como la eficiencia, eficacia y calidad son necesarios en la medida que atienden a la consecución del fin que persigue la administración de la res pública. En este sentido, hablar de eficacia no es incompatible con el derecho administrativo pues finalmente son principios arraigados en la doctrina ${ }^{6}$ y la legislación. En la forma de gestión pública estos términos implican, entre otras cuestiones, el cumplimiento de obligaciones previstas en la norma y el ejercicio de potestades administrativas.

\section{La construcción de la gobernanza desde la globalización}

Diversos autores como Aguilar Villanueva ${ }^{7}$ y Closa Montero ${ }^{8}$ así como organismos internacionales como el Banco Mundial, el Fondo Monetario Internacional o la Organización para la Cooperación y Desarrollo Económico (OCDE), comienzan a emplear la palabra gobernanza a finales del siglo XX. Los autores, desde la doctrina, inician su labor académica abarcando el estudio de las relaciones entre el Estado y la sociedad a través de la participación, la transparencia, eficacia, rendición de cuentas, etcétera, mientras que los organismos internacionales, lo emplean no sólo en sus discursos sino también las políticas y compromisos a los que sujetan a los países miembros. De esta manera procuran difundir políticas de gestión en las regiones sobre las que tienen influencia. Este mecanismo de actuación se concreta a través del establecimiento de criterios en las normas, buscando, de esta manera que se vean aplicados en las instituciones públicas finalmente.

La globalización y la gobernanza son fenómenos contemporáneos a partir de los años noventa. La coincidencia viene dada por la intervención de organismos internacionales en la apertura de mercados $^{9}$ y su inclusión en lo público ${ }^{10}$. En este último aspecto, la apuesta de los organismos internacionales no sólo abarca los aspectos más técnicos sino también aquellos que legitiman el poder en torno a la eficiencia y la participación democrática. Una concepción de democracia a medida construida desde los organismos supranacionales que, bajo la influencia económica,

5 Domínguez Uribe, Alejandro, "La gobernanza y sus implicaciones” en: Pérez F. G. y González U. P (coords.) en Tendencias actuales de la ciencia política. Temas de análisis para comprender un mundo en cambio, Tomo II, UNAM, México, pp. 94 y 95.

6 Luciano Parejo, Alfonso (1995), Eficacia y administración, Madrid, Ministerio para las Administraciones Públicas, INAP y Ministerio de la Presidencia, 105-109.

7 En esta obra el autor hace una breve explicación sobre el concepto de gobernanza, su significado y sus aspectos primordiales. Aguilar Villanueva, Luis (2007), "El aporte de la política pública y de la nueva gestión Pública a la gobernanza", Revista del Centro Latinoamericano de Administración para el Desarrollo, Reforma y Democracia, Caracas, Núm. 39, Octubre, pp. 7 y 8.

8 Closa Montero, Carlos (2003), “El libro Blanco sobre la gobernanza”, Revista de Estudios Políticos, España, Núm. 119, p. 485.

9 Aguilar Villanueva, Luis (2014), “De la gobernabilidad a la gobernanza”, Examen, México, año XXIII, Núm. 234, septiembre, p. 35.

10 Fernández González, Miguel Angel (2012), “Globalización: Rol de derecho público y transformación del Estado", Revista chilena de derecho, Chile, Núm. 187, 2012, pp. 305-326; BRITo, Mariano (2002), "Globalización y Derecho Administrativo", Ius Publicum, España, Núm. 9, pp. 47-54. 
esperan facilitar la transición de los países hacia una sociedad y unas organizaciones públicas ávidas de movilidad.

El concepto de gobernanza atiende a connotaciones principalmente económicas y políticas para después repercutir en el ámbito jurídico. La doctrina reconoce que el uso del concepto de gobernanza surge a través de dos documentos internacionales hacia finales del siglo XX: El Consenso de Washington y la Declaración del Milenio. En estos instrumentos internacionales se utiliza con una connotación distinta respecto de la que tuvo en suorigen ${ }^{11}$, ya que con este concepto se buscaba dar respuesta a un fenómeno económico complejo, como la globalización.

El primero de los documentos, el Consenso de Washington, estableció lineamientos políticos así como un modelo económico neoliberalista. Impulsado por Organizaciones Internacionales como el Fondo Monetario Internacional y el Banco Mundial su finalidad era propiciar el desarrollo de los países subdesarrollados, por desgracia no tuvo el éxito esperado y los resultados de esta imposición afectaron gravemente el desarrollo económico de los países en vías de desarrollo por diversas causas. Debido a las fuertes críticas que recibe este acuerdo, en el año 2000 se firma la Declaración del Milenio, que [...] contiene recomendaciones específicas para la mejor gobernanza y la correcta función pública, cuya eficacia resulta crucial para la implementación de un nuevo paradigma del desarrollo ${ }^{12}$, además propone ideas incluyentes respecto a las políticas económicas globales y sugiere autonomía para solucionar conflictos de acuerdo a sus propias circunstancias, de manera que la globalización no excluya lo local/nacional, sino que lo haga más visible ${ }^{13}$. El contexto globalizador en el que se desarrolló la gobernanza ha dado lugar a una confusión de términos y efectos, lo cual no siempre ha sido perjudicial pues como resultado de las opiniones vertidas en este sentido el concepto de gobernanza ha evolucionado $\mathrm{y}$, a la par de los aspectos económicos u organizacionales, aborda los aspectos jurídicos en el ámbito de cada país y sus respectivas necesidades.

\section{La gobernanza como instrumento de planeación política y administrativa}

La gobernanza es un concepto transversal que puede permear diversas áreas. Su significado entonces es variado, con elementos propios que le han permitido su redefinición al paso del tiempo. A manera de ejemplo, organismos internacionales, a finales del siglo XX, se incursionaron en definir este fenómeno; la Organización de Cooperación para el Desarrollo Económico (OCDE), definió gobernanza de una manera general diciendo que: es la suma de las numerosas maneras cómo los individuos y las organizaciones públicas y privadas dirigen y manejan sus asuntos comunes ${ }^{14}$. Posteriormente en 1997, el Programa de las Naciones Unidas para el Desarrollo (PNUD) trabajó en la construcción del concepto integrando y especificando ciertos elementos para ampliar la definición y determinar lo siguiente [...] es el ejercicio de autoridad política, económica y administrativa para manejar los asuntos de la nación. Es un complejo de

\footnotetext{
${ }^{11}$ La palabra gobernanza no es nueva ya que surge en Francia y se introduce al inglés en el siglo XIV, sin embargo, sí se le dio un nuevo el significado ya que en aquel tiempo significaba gobierno, un gobierno que se entendía propio del antiguo régimen autoritario. Solá, Amadeu (200o), "La traducción de gobernanza", Punto y Coma, núm. 65, septiembre-octubre, [en línea], disponible en: http://ec.europa.eu/translation/bulletins/puntoycoma/65/ pyc652.htm.

12 Barros Valero, Javier (2009), “América Latina y México. Administración pública y gobernanza”, Revista de Administración Pública, México, vol. XLIV, núm. 3, septiembre-diciembre, p. 148.

${ }^{13}$ Ibídem. p. 149.

${ }^{14}$ Governance in Transition. Public Management reforms in OECD Countries, París, 1995.
} 
mecanismos, procesos, relaciones e instituciones por medio de los cuales los ciudadanos y los grupos articulan sus intereses, ejercen sus derechos y obligaciones y median sus diferencias ${ }^{15}$.

Ambas definiciones, describen el concepto de gobernanza como un modelo de gestión pública; tratándose de la definición, propuesta por el Programa de las Naciones Unidas para el Desarrollo, observamos la repercusión que la gobernanza genera en tres de las principales esferas en las que el Estado participa activamente: la económica, la política y lo administrativo.

En el ámbito propiamente administrativo, la aplicación de un determinado modelo de gestión pública fortalece la capacidad administrativa y de respuesta del Estado, favoreciendo, además, la obtención de resultados ${ }^{16}$. Para los fines de esta investigación utilizaremos el término de gobernanza como un modelo de gestión pública, cuya característica principal del Estado es priorizar la cooperación e integración de otros sectores en las actividades de gobierno. Bajo este contexto se puede decir que gobernanza surge de la manifestación de cambios ocurridos en la teoría como en la práctica acerca de lo que es el Estado y lo que debiera ser ${ }^{17}$.

Por otra parte, existen dos perspectivas bajo las cuales puede ser analizada la gobernanza: descriptiva y prescriptiva ${ }^{18}$. La primera se refiere a la evolución de la relación Estado- sociedad desde finales del siglo XX. La segunda abarca aspectos normativos en donde debiera estar establecida la forma apropiada, correcta y eficaz de gobernar un país ${ }^{19}$.

El segundo aspecto tiene traducción en la regulación normativa de la actuación de las administraciones públicas que reflejan, en la mayoría de las situaciones de facto, poca eficiencia, con respuestas tardadas para dar solución a un problema, incumpliendo deberes de actuación impuestos por la norma. En este sentido es preocupante que en el plano normativo, como es el caso de México, encontramos formalizada la tolerancia de la inactividad administrativa procedimental o formal bajo la figura del silencio administrativo. Es así que surge la necesidad de valorar la importancia de la gobernanza no sólo en la forma de gobierno, sino que éste se extienda hasta el ordenamiento jurídico dentro de las instituciones para poder hablar de una verdadera relación armónica entre el Estado, órganos administrativos y sociedad.

\section{Legalidad y gobernanza frente a la inactividad de la Administración}

La actuación de las administraciones públicas se ve sujeta al principio de legalidad, de ahí que es necesario insistir en la importancia de que los argumentos que se viertan en la investigación se sujeten a la existencia de deberes de actuación. Ello es posible porque la gobernanza implica que el ordenamiento sea comprensible y accesible a los ciudadanos y que, en esta medida, los legisladores incorporen a la ley expresiones normativas de una forma de gestión abierta y cercana al ciudadano. Tras este presupuesto, los tribunales podrán resolver si las autoridades se han o no apegado a la norma favoreciendo el mejor desarrollo en la vida digna2o. El principio de

${ }^{15}$ UNDP, Reconceptualising Governance, Discusión paper núm 2, Management Development and Governance, División, Bureau for Policy and Programme Support, UNDP, Nueva York, enero de 1997, p. 9.

16 SÁnchez GonzÁlez, José (2002), Gestión pública y governance, México, Instituto de Administración Pública del Estado de México, p. 298.

${ }^{17}$ Ibídem. p. 37.

${ }^{18}$ Aguilar Villanueva, Luis (2008), Gobernanza y gestión pública, México, Fondo de Cultura Económica, p. 84.

${ }^{19}$ Serna De La Garza, José María (2010), Globalización y gobernanza: las transformaciones del estado y sus implicaciones para el derecho público: contribución para una interpretación del caso de la guardería $A B C$, México, UNAM-Instituto de Investigaciones Jurídicas, p. 22

${ }^{20}$ García De Enterría, Eduardo (2004), La Revolución Francesa y Administración contemporánea, Madrid, Civitas, p. 20; del mismo autor (2009), Democracia, jueces y control de la Administración, VI edición, Cizur Menor, Aranzadi, pp. 55 y ss. 
legalidad encuentra en el Derecho administrativo un campo natural de acción en el marco del Estado de Derecho moderno en el que se ha dicho que, si bien el principio de legalidad a partir de la Revolución francesa se ha constituido como un eje vertebrador del quehacer de las autoridades, lo cierto es que en la actualidad éste ha adquirido características de sistematización ${ }^{21}$.

\section{Gobernanza y Estado de Derecho}

El Banco Mundial identifica cinco funciones ${ }^{22}$ que los sistemas jurídicos debían desempeñar para apoyar el Estado de derecho analizados desde una perspectiva relacionada a la gobernanza. Primero, proveer un conjunto de normas conocidas de antemano, lo cual sugiere que el Estado contemple los medios necesarios para informar a la sociedad del ordenamiento jurídico, los procesos y procedimientos dentro de la administración, pero también es cierto que el Estado no contempla los medios necesarios para informar a la sociedad de los aspectos jurídicos que rodean a las administraciones públicas, incluido el régimen del silencio administrativo, que en sí mismo sería contrario desde una perspectiva jurídica y política a los principios de la gobernanza. Entre otros aspectos, se debe poner de relieve que la inactividad administrativa también se implica en el derecho a la información pues es necesario que los servidores públicos informen sobre las normas empleadas, no sólo al abogado, sino a todas las personas que así lo requieran, a través de campañas o un lenguaje jurídico entendible para cualquier individuo.

Segundo, sobre la aplicación efectiva de normas se debe señalar que es posible que las administraciones públicas diseñen procedimientos sencillos con base en el conocimiento de las instituciones jurídicas así como de las necesidades y problemáticas cotidianas. Esto permitiría que las reglas de operación faciliten que se otorgue una respuesta expresa al ciudadano evitando así que los servidores públicos vean en el procedimiento el primer elemento de desánimo para cumplir con la obligación de resolver.

Tercero, la aplicación general de reglas, incluyendo a los servidores públicos, además implica que el ordenamiento ponga énfasis en que los servidores públicos encuentren consecuencias jurídicas ante el incumplimiento de sus deberes. En este sentido, el sistema de responsabilidad de los servidores públicos juega un papel esencial para dar seguimiento a los casos en que la inactividad administrativa produce efectos perjudiciales al ciudadano.

Cuarto, la efectividad y autonomía de los órganos judiciales respecto a las resoluciones de disputas, ante la inactividad administrativa y la gobernanza, exigiría que los procesos judiciales se lleven a cabo con transparencia y honestidad. Se debe recordar de antemano que la carga ante la pasividad de la autoridad recae en el ciudadano.

Quinto, implica transparencia en las normas así como el establecimiento de mecanismos para la introducción o eliminación de estas. Es indispensable que los Estados reconozcan la trascendencia de la inactividad administrativa para evidenciar la ineficiencia de los procesos legislativos. Esta situación puede observarse desde dos perspectivas, la responsabilidad del Estado legislador y la responsabilidad de las administraciones de dictar los reglamentos que las normas prevén. Ambos casos ya han sido desarrollados en las normas pero su aplicabilidad se ve mermada por la falta de información a los particulares que habitualmente toleran la pasividad frente a deberes normativos.

$\mathrm{Si}$ bien los organismos internacionales antes señalados se ajustan a reglas propias de la economía de mercado que prima para las grandes potencias mundiales y no siempre atienden a las particularidades de los Estados en proceso de desarrollo, lo cierto es que estas recomendaciones

\footnotetext{
${ }^{21}$ Alli-Aranguren, Juan Cruz (2004), Derecho administrativo y globalización, Madrid, Civitas, p. 126.

22 SERnA op. cit. nota 19, pp. 38-39.
} 
se pueden adecuar a las necesidades de nuestro país recogiendo los aspectos más útiles para propiciar una mejor relación entre las administraciones públicas y los ciudadanos que merecen un mejor trato. Los lineamientos empleados por el Banco Mundial posteriormente fueron empleados en las administraciones públicas de los Estados para cumplir con los estándares de la gobernanza, sin embargo, los resultados no fueron satisfactorios para los países que buscaban favorecer el desarrollo pues la implementación de políticas exclusivamente económicas y generales impidieron el avance de las economías emergentes.

A través de la Declaración del Milenio, firmada por los países integrantes de la ONU en el año 2000, se hace una reconsideración sobre los elementos (entre ellos la gobernanza) que debieran considerarse para propiciar el desarrollo y erradicar la pobreza ${ }^{23}$, dejando de lado aquella visión en donde la economía jugaba el papel principal como único elemento imprescindible para lograrlo. Como parte del seguimiento que se le ha dado a este documento por parte del organismo internacional ya mencionado, se han realizado varias reuniones oficiales con el objetivo de evaluar el desempeño realizado en el cumplimiento de los compromisos adquiridos. De los documentos que resultaron de estas intervenciones de planeación y evaluación se reconoce la importancia de implementar la gobernanza dentro de la gestión de los asuntos públicos y en todos los niveles de gobierno para para favorecer el desarrollo de economías en transición.

Como ya se ha mencionado con anterioridad, este instrumento internacional contempla no sólo aspectos económicos, sino también políticos, sociales, culturales y jurídicos, este último elemento queda establecido así en el 2010 mediante uno de los documentos que dan continuidad a la Declaración del Milenio. Este reconoce a la buena gobernanza y el Estado de derecho (en cualquiera de sus ámbito de aplicación: nacional e internacional), como pilares fundamentales en la construcción de sociedades justas y democráticas para el desarrollo ${ }^{24}$.

\section{La buena administración, expresión jurídica de la gobernanza en el combate a la inactividad}

Los principios generales del derecho son, en la rama del derecho administrativo, un instrumento clave contra los abusos e ilegalidades de las administraciones públicas, debido a las funciones que desempeñan durante su aplicación, permitiendo así comprender la utilidad y los límites de esta rama de derecho público ${ }^{25}$. En el tema de la inactividad, el principio a la buena administración tiene un significado trascendental pues retoma características democráticas dentro del aparato administrativo del Estado, lo cual implica para las Administraciones públicas servir objetivamente a la ciudadanía, realizar su trabajo con racionalidad, justificar sus actuaciones y

\footnotetext{
${ }^{23}$ La Declaración del Milenio suscrita en Nueva York el d13 de septiembre del año 200o, hace mención exclusivamente de la gobernanza en el apartado III, párrafo 13, al referirse a esta como buena gestión de los asuntos públicos.

${ }^{24}$ Cumplir con la promesa: unidos para lograr los Objetivos de Desarrollo del Milenio, suscrito en Nueva York el 19 de octubre de 2010, en el párrafo 11, incluye en su discurso buena gobernanza, la cual hace referencia a la manera en que los actores, que participan con el Estado, cumplen los lineamientos establecidos por la gobernanza. Ponce Solé, Julie (2012), Buena administración, Diccionario de Derechos Humanos, Universidad de Alcalá, [en línea], disponible en: http://diccionario.pradpi.org/inicio/index.php/terminos_pub/to_pdf/4o.

25 Sánchez Morón, Miguel (2008), Derecho Administrativo. Parte general, $4^{\circ}$ Ed. Tecnos, Madrid, pp.122-125. En esta obra el autor hace mención de las distintas funciones que deben cumplir los principios generales del Derecho (informadora, interpretativa y supletoria), además resalta la importancia de la clasificación de los mismos pues los considera numerosos y heterogéneos.
} 
que estas se dirijan continuamente al interés general considerando en todo momento, la mejora permanente e integral de las condiciones de vida de las personas ${ }^{26}$.

La noción de buena administración puede observarse desde distintas perspectivas: la política, económica y por supuesto en la ciencia de la administración. En la esfera jurídica ha costado mucho tiempo su construcción por las características de indeterminación que fueron observadas en un principio. Sin embargo, una comprensión amplia de la aplicación de principios de derecho en su momento comenzaron a permear en las resoluciones de algunos tribunales europeos y algunos otros operadores jurídicos ${ }^{27}$. Incluso las críticas por la amplitud o indeterminación de la buena administración han encontrado un contraargumento interesante pues implica un contenido rico de elementos regulatorios de la actividad de las administraciones públicas como el factor tiempo, el debido proceso, acceso a la información pública, entre otros ${ }^{28}$.

Un gran paso para hablar sobre el derecho a la buena administración y ya no sólo como un conjunto de principios articulados a deberes genéricos es la firma de la Carta de los Derechos fundamentales de la Unión Europea en el año 2000. En este documento el artículo 41 reconoce el derecho a una buena administración y éste se ha configurado de como: Toda persona tiene derecho a que las instituciones y órganos de la Unión traten sus asuntos imparcial y equitativamente y dentro de un plazo razonable. Además de incluir, en este mismo apartado, tres derechos de igual relevancia:

-El derecho de toda persona a ser oída antes de que se tome en contra suya una medida individual que le afecte desfavorablemente.

-El derecho de toda persona a acceder al expediente que le afecte dentro del respeto de los intereses legítimos de la confidencialidad y del secreto profesional y comercial y,

-La obligación que incumbe a la administración de motivar sus decisiones.

La inclusión del concepto de gobernanza dentro de instrumentos jurídicos internacionales ha generado una serie de transformaciones en los distintos ámbitos en los que el Estado interviene y, para el caso de las administraciones públicas, la repercusión recae en el derecho administrativo, incluso sobre la actividad procedimental. Hablar de gobernanza nos lleva a reflexionar sobre el principio (o derecho, según sea considerado en la legislación de cada país) a la

\footnotetext{
${ }^{26}$ Rodríguez Arana, Jaime (2013), "La buena administración como principio y como derecho fundamental en Europa”, Misión Jurídica, Bogotá Colombia, núm. 6, enero-diciembre, p. 26.

27 Un ejemplo lo constituye el análisis realizado en relación con la función consultiva particularmente en materia urbanística. Amilivia González, Mario y Nalda García (2008), José C. en: "Principios de buena administración y función consultiva”, Revista Española de la Función Consultiva, No. 9 de; también en materia urbanística véase, Ponce SolÉ, Julio (2008), "Desarrollo territorial sostenible y buena administración mediante la actividad de planificación en la Ley 8/2007, de 28 de mayo, de suelo" en: El derecho urbanístico del siglo XXI: Libro homenaje a Martín Bassols Coma, Editorial Reus, pp. 487-548; SÁnchez BlAnCo, Ángel (20o8), "De la actividad archivística como función pública y de su incidencia en los derechos de los ciudadanos y en la buena administración”, Revista General de Derecho Administrativo, No. 17.

${ }^{28}$ PONCE SolÉ, Juli (2001), El deber de buena administración y el derecho al procedimiento administrativo debido. Las bases constitucionales del procedimiento administrativo y del ejercicio de la discrecionalidad, Valladolid, Lex Nova, p. 127 y ss. Resulta significativo que L. N. González Alonso que amplitud del derecho a la buena administración representa una ventaja pues no tiene un "contenido cerrado, sino cambiante y evolutivo", véase, GonzÁLez Alonso, Luis N. (2008), Derecho a una buena administración en: Carta de los derechos fundamentales de la Unión Europea: Comentario artículo por artículo, Fundación BBVA, Madrid, p. 670.
} 
buena administración. Ambos desde sus propios postulados colocan al ciudadano como pieza clave en la actividad de la administración.

El principio a la buena administración y su reconocimiento en alguno de los ordenamientos jurídicos de México, resultaba ser un tema pendiente en la agenda de los legisladores hasta que, la reciente transformación del Distrito Federal a un Estado más de la federación trajo consigo la creación de un proyecto de Constitución $\operatorname{local}^{29}$ que ha incluido a la buena administración como un derecho fundamental. En el proyecto de Constitución se hizo una descripción de las implicaciones de este derecho en la actividad procedimental de las administraciones públicas. El artículo 12 retomó los elementos descritos en el artículo 41 de la de la Carta de Derechos Fundamentales de la Unión Europea (imparcialidad, resoluciones en plazo razonable, debido proceso administrativo, audiencia previa, respuesta a las peticiones, fundar y motivar resoluciones, y reparación de daños entre otros). Además reservó un capítulo propio a la buena administración que da inicio con el artículo 66, en donde se abordó con una perspectiva orientada al servidor público, resaltando la importancia de la profesionalización de estos bajo los principios establecidos por la buena administración.

Los postulados que establece la buena administración, tienen repercusión cuando se refiere a la actividad procedimental de la administración, pues en el caso de México la consideración del plazo razonable supone una consideración especial a la regulación de la actuación de la administración pública, por ejemplo, tratándose del derecho de petición consagrado en el artículo 8 de la Constitución mexicana que obliga a la administración a brindar una respuesta ante una solicitud del ciudadano y que se ve vulnerado por la inactividad administrativa tolerada bajo la figura del silencio administrativo ${ }^{30}$.

La consolidación del derecho a la buena administración en el proyecto de Constitución de la ciudad de México, parecía sentar las bases jurídicas para la protección del ciudadano frente a las acciones y omisiones de la administración pública. Sin embargo, en la publicación definitiva de la Constitución se restringen los alcances de la buena administración, dejando a un lado la perspectiva amplia que mantenía el proyecto constitucional en su artículo 12 para considerar, principalmente, la actividad material de las administraciones públicas ${ }^{31}$. Se entiende que esta regulación material es importante, pero cuando se trata de buena administración, deben fortalecerse ambas perspectivas de la actuación administrativa, material y formal.

Es indiscutible la importancia que tiene en el ámbito jurídico y social la adecuada articulación de principios de actuación coherentes con la buena administración y la gobernanza (si pensamos en un derecho administrativo mínimo) por lo que su reconocimiento por el derecho positivo favorece la evolución de un sistema normativo anclado en una compresión decimonónica de la sociedad, autoridades y derecho. Europa, han conseguido reconocer al ciudadano un

${ }^{29}$ Proyecto de Constitución Política de la Ciudad de México, presentada el 15 de septiembre de 2016, [en línea], disponible en: http://gaceta.diputados.gob.mx/ACCM/DOC/ProyectoConst15sep.pdf.

30 Nettel Barrera, A. (2012), Obligación de resolver, silencio administrativo y responsabilidad patrimonial por inactividad. Una perspectiva de comparación entre el Derecho español y mexicano, Barcelona, Atelier, p.421 y ss.

${ }^{31}$ El texto aprobado de la Constitución hace mención del derecho a la buena administración en los artículos 3, 7 (apartado A) y 6o. De manera general, el documento ajusta el ejercicio del poder al derecho a la buena administración, establece estándares de calidad en la prestación de servicios públicos y, por otro lado, aborda aspectos procedimentales cuando se refiere a la audiencia previa, el plazo razonable y la formalidad del procedimiento. Además, se amplía la competencia al Tribunal de Justicia Administrativa de la entidad para conocer de los recursos que interpongan ciudadanos por el incumplimiento de las medidas de debido proceso relativas al derecho a la buena administración y por último incorpora el tema de la buena administración en las alcaldías. Constitución Política de la Ciudad de México, publicada el 5 de febrero de 2017, [en línea], disponible en: http://www. cdmx.gob.mx/storage/app/uploads/public/589/746/ef5/589746ef5f8cc447475176.pdf. 
derecho fundamental 32 que presupone mayor seguridad jurídica frente a la actuación y omisión de la administración pues no está supeditado a la voluntad de ésta, por otra parte impone para las administraciones públicas la obligación de administrar adecuadamente los asuntos públi$\cos ^{33}$.

\section{La protección de los derechos humanos vulnerados por la inactividad administrativa}

Hablar de gobernanza y buena administración necesariamente implica hablar de derechos humanos. Bajo el paradigma constitucional mexicano, las autoridades administrativas tienen la obligación de respetar, promover, proteger y garantizar los derechos de los ciudadanos y ello implica reconocer que la protección de los intereses generales, a partir de 2011, se debe hacer desde una perspectiva humanista coherente con el ordenamiento jurídico. En este contexto, el centro de gravedad es el ciudadano y los deberes de actuación previstos por la norma son irrenunciables siempre que afecten derechos fundamentales, entendidos estos como los derechos humanos reconocidos por la norma en nuestro Estado. Esta concepción del poder público ejercida en un Estado de derecho es el fundamento de la concreción de la buena administración.

En este sentido, es importante que se analicen las causas y consecuencias de la vulneración de derechos humanos así como la posición que guarda la administración frente a deberes de actuación específicos que les garantizan la protección de derechos humanos. Por lo que respecta a esta investigación, las obligaciones de actuación se limitan a observar la inactividad administrativa en el marco de un procedimiento como vulneración de un derecho humano: el derecho de petición, consagrado en el artículo 8 de la Constitución mexicana. El ámbito procedimental, en sí mismo, es el medio para la producción de actos administrativos y la principal vía de comunicación entre la administración y los particulares, de ahí que, como ya hemos tenido oportunidad de observar, el artículo 41 de la Carta de los Derechos Fundamentales reconoce en la buena administración el procedimiento o, dicho en sus términos, el trato de los asuntos de las personas.

A partir de la segunda mitad del siglo XX se han puesto en funcionamiento diversos instrumentos jurídicos para la protección de los derechos humanos dirigidos a las autoridades administrativas ${ }^{34}$ para quienes no es admisible su inactividad si de esto depende la protección de derechos humanos, principalmente tratándose de derechos económicos, sociales y culturales $^{35}$. Desde la Convención de Derechos Humanos y Libertades Fundamentales hasta la Carta de Derechos Fundamentales de la Unión Europea, pasando por el Convenio Americano sobre Derechos Humanos (Pacto de San José de Costa Rica) y el Protocolo de San Salvador, ha habido una evolución en el que una vez consolidados los derechos humanos más esenciales debe avanzarse en la concreción de otros derechos en sociedades cada vez más complejas en que

\footnotetext{
${ }^{32}$ Se puede decir que el reconocimiento a este principio, además de considerarse como una avance respecto al papel que juega el ciudadano dentro del actuar de la administración, es una configuración de un verdadero derecho fundamental de los derechos de ciudadanía, de naturaleza cambiante y evolutiva, que reconoce a toda persona. Véase GonZÁLEZ, op. cit. nota 28, p. 668.

${ }^{33}$ Rodríguez op. cit. nota 26, p. 78.

${ }^{34}$ Rodríguez Pontón, Francisco José (2005), La articulación de las garantías administrativas y jurisdiccionales en el sistema del CEDH, Thomson-Civitas, Cizur Menor, In totum, parisio, Vera (dir., 201o), Diritti interni, diritto comunitario e principi sovranazionali, Giuffrè, Milán.

${ }^{35}$ El Doctor Witker menciona que el Art. 1 de la Constitución de México obliga a todas las autoridades del Estado mexicano a velar por la protección y garantía de derechos humanos, incluidos los Derechos económicos, sociales y culturales. WitKer, Jorge (2015), "El derecho económico y los derechos sociales en la gobernanza actual” en: Carbonell Miguel y Cruz Oscar (coords.), Historia y Constitución. Homenaje a José Luis Soberanes Fernández, México, UNAM- IIJUNAM, t. I, p.52o.
} 
las autoridades públicas adquieren un papel activo ${ }^{36}$. Entre estos derechos, los referidos a una buena gestión pública deben adquirir, sin lugar a dudas, un lugar preeminente para evitar que el ciudadano vea reducido su papel a un mero actor secundario.

En este sentido, los instrumentos internacionales han promovido un parámetro amplio de actuación para los poderes públicos, particularmente, para las administraciones públicas, en favor de los ciudadanos. Como resultado de este fenómeno internacional, en la actualidad todas las autoridades mexicanas tienen el deber de promover, respetar, proteger y garantizar los derechos humanos de acuerdo a una serie de principios reconocidos por la Constitución. Como ha señalado M. Carbonell, el derecho internacional a través de los actos, tratados, observaciones generales, etcétera, permite advertir los distintos tipos de obligaciones que generan los derechos fundamentales para los poderes públicos ${ }^{37}$ tanto generales como específicas de tal suerte que el contenido del párrafo tercero del artículo 1 de la Constitución mexicana signifique actuaciones concretas para las autoridades administrativas en todos los niveles de gobierno. La reforma constitucional en materia de derechos humanos llevada a cabo en el año 2011 ha supuesto para México un cambio de paradigma en la comprensión de la tutela de los derechos humanos pues anteriormente sólo los derechos reconocidos en la Constitución como garantías de los ciudadanos tenían una entidad suficiente para protegerlos de la actuación de los poderes públicos.

En el contexto de la actividad de las administraciones públicas el procedimiento se configura como un elemento primordial, a partir del cual se toman decisiones que producirán efectos jurídicos en la vida de los ciudadanos aunque esto no sea fácilmente observable. Esto tiene origen en dos factores: primero la deficiente regulación y transparencia en los procedimientos administrativos y segundo en los pocos espacios de participación ciudadana que prevea canales de comunicación eficientes entre la administración y los ciudadanos. Sin embargo, su importancia es incuestionable, pues independientemente de su iniciación (oficiosa o a petición de parte), a través de éste se emite una resolución que tendrá una repercusión en la realidad material que afecta, tal vez, algún derecho fundamental. Se trata del ejercicio de las potestades que el ordenamiento ha conferido a la administración, precisamente para que las ejercite, desde la perspectiva constitucional, el artículo 8 de la Constitución mexicana establece el derecho de petición y la jurisprudencia constitucional ha reconocido un derecho de respuesta por lo que no existe justificación para incumplir con este deber expreso y además notificarlo ${ }^{38}$.

Frente a la vulneración del derecho de petición y la inactividad procedimental, la legislación ha producido la figura del silencio administrativo para evitar la indefensión de los ciudadanos en un sistema de impugnación basado en la existencia del acto administrativo. La producción

\footnotetext{
${ }^{36}$ Ferrajoli, Luigi (2016) “Sobre los Derechos Fundamentales”, Cuestiones Constitucionales Revista Mexicana de Derecho Constitucional, Trad. Miguel Carbonell, núm. 15, UNAM, julio-diciembre.

37 Carbonell, Miguel (2012) "Las obligaciones del Estado en el artículo $1^{\circ}$ de la Constitución mexicana", en: $L a$ reforma constitucional de derechos humanos. Un nuevo paradigma, CARBONELL, M. y SAlAZAR, P. (coords.), Porrúa-UNAM, México, pp. 75-85. El autor señala, con fundamento en la Observación General 3 del Comité de Derechos Económicos, Sociales y Culturales de la ONU, qué se debe entender por respetar (abstenerse hacer cualquier cosa que viole la integridad de los individuos o grupos sociales o ponga en peligro la integridad de los individuos), proteger (adopción de medidas destinadas a evitar que otros agentes o sujetos violen los derechos fundamentales, a través de esquemas reactivos y preventivos) y cumplir o realizar (adopción de medidas activas incluyendo acciones positivas a favor de grupos vulnerables) las obligaciones del Estado en materia de derechos fundamentales.

${ }^{38}$ Artículo 8 de la Constitución Política de los Estados Unidos Mexicanos:
}

Los funcionarios y empleados públicos respetarán el ejercicio del derecho de petición, siempre que ésta se formule por escrito, de manera pacífica y respetuosa; pero en materia política sólo podrán hacer uso de ese derecho los ciudadanos de la República. 
del silencio en su vertiente negativa implica que el particular pueda recurrir a la jurisdicción contencioso administrativa a anular la ficción de acto llamado negativa ficta. En su vertiente positiva implica que la ley previó que ante la ausencia de resolución expresa se estimará la petición del particular. Si bien se puede distinguir entre los efectos positivos o negativos en una y otra figura lo cierto es que ambas representan un incumplimiento de deberes y es la expresión de una mala práctica. Incluso en el caso del silencio positivo se debe destacar que al no haber concluido de manera exitosa el procedimiento administrativo de origen lo cierto es que no se evaluaron los intereses presentes y no hay constancia del cómo y por qué de la resolución, pues no hay tal. Bajo el supuesto de inactividad procedimental, la administración no está dando un trato adecuado a los asuntos de los particulares pues simplemente no los está atendiendo.

La fracción X del artículo 16 de la Ley Federal de Procedimiento Administrativo prevé la obligación de las administraciones públicas de Dictar resolución expresa sobre cuantas peticiones le formulen; así como en los procedimientos iniciados de oficio, cuya instrucción y resolución afecte a terceros, debiendo dictarla dentro del plazo fijado por la ley. Esta es la primera piedra de la construcción del derecho a la buena administración pues es una obligación ya impuesta a las administraciones. Sin embargo, en la misma ley de procedimiento, en el artículo 17, se prevé la producción del silencio administrativo lo que implica una tolerancia y contradicción con el deber de resolver. Si bien, como ya había señalado, el silencio negativo permite el acceso a la justicia administrativa no deja de implicar una vulneración de derechos lo que habría de hacer exigible una acción de resarcimiento por las cargas procesales que implica la impugnación de la negativa ficta.

La buena administración y su reconocimiento formal como un derecho en instrumentos internacionales latinoamericanos no ha sido posible. Pese a esto, los criterios jurisprudenciales de la Corte Interamericana ha tenido la oportunidad de sentar las bases de su estructura y de la trascendencia del procedimiento administrativo $-\mathrm{y}$ su resolución en un plazo razonablepara la protección de los derechos humanos. En este sentido se ha hecho referencia al debido proceso judicial en el marco de las garantías que éste ofrece y, en sí mismo, se ha configurado como un derecho humano. En el ámbito jurisdiccional el derecho a las garantías del proceso o el proceso debido se ha consolidado para reaccionar contra las irregularidades procesales que afectan otros derechos humanos y en esta misma medida ha trascendido al ámbito administrativo. Al respecto, el caso Baena Ricardo y otros Vs. Panamá ${ }^{39}$ constituye uno de los precedentes más importantes al reconocer que 270 trabajadores del Estado, despedidos por participar en una manifestación, no tuvieron oportunidad de ser oídos en un procedimiento administrativo previo antes de aplicarles una sanción disciplinaria tan grave como la destitución. La Corte consideró que

Si bien el artículo 8 de la Convención Americana se titula 'Garantías Judiciales', su aplicación no se limita a los recursos judiciales en sentido estricto, <sino [al] conjunto de requisitos que deben observarse en las instancias procesales $>$ a efectos de que las personas estén en condiciones de defender adecuadamente sus derechos ante cualquier tipo de acto del Estado que pueda afectarlos. Es decir, cualquier actuación u omisión de los órganos estatales dentro de

A toda petición deberá recaer un acuerdo escrito de la autoridad a quien se haya dirigido, la cual tiene obligación de hacerlo conocer en breve término al peticionario.

${ }^{39}$ Caso Baena Ricardo. Sentencia Corte IDH de 2 de febrero de 2001. Serie C No. 72 
un proceso, sea administrativo sancionatorio o jurisdiccional, debe respetar el debido proceso legal ${ }^{40}$.

En un primer momento la Corte hace referencia a los procedimientos sancionatorios por su naturaleza como una expresión del poder punitivo del Estado y de ahí que se legitime su control, sin embargo, en otro apartado señala que el alcance del debido proceso es amplio ${ }^{41}$ y que Es un derecho humano el obtener todas las garantías que permitan alcanzar decisiones justas, no estando la administración excluida de cumplir con este deber. Las garantías mínimas deben respetarse en el procedimiento administrativo y en cualquier otro procedimiento cuya decisión pueda afectar los derechos de las personas ${ }^{42}$.

Otro aspecto procedimental atendido por la Corte Interamericana es la motivación de las resoluciones, a partir de una interpretación amplia del artículo 8 del Pacto ${ }^{43}$. El primer apartado del artículo señala

Toda persona tiene derecho a ser oída, con las debidas garantías y dentro de un plazo razonable, por un juez o tribunal competente, independiente e imparcial, establecido con anterioridad por la ley, en la sustanciación de cualquier acusación penal formulada contra ella, o para la determinación de sus derechos y obligaciones de orden civil, laboral, fiscal o de cualquier otro carácter.

En este sentido la Corte consideró que el debido proceso legal debe respetarse en el procedimiento administrativo y en cualquier otro procedimiento cuya decisión pueda afectar los derechos de las personas ${ }^{44}$, como en el caso Claude Reyes y otros vs. Chile, de 19 de septiembre de 2006, Serie C No. $151^{45}$ y el cumplimiento de la administración de plazos razonables para tramitar y resolver, en función de tres elementos: comportamiento del administrado, complejidad del caso, diligencia en la conducta de la administración señalado en el caso Comunidad indígena Yakye Axa vs. República del Paraguay ${ }^{46}$ de 17 de junio de 2005, Serie C, No. 125. En esta sentencia se consideró, en orden a la importancia de la actuación oportuna de la administración, que la complejidad de este procedimiento era mínima y que el Estado no ha justificado la mencionada

${ }^{40}$ Apartado 124. Caso Baena Ricardo Sentencia Corte IDH de 2 de febrero de 2001. Serie C No. 72

41 Apartado 125.

La Corte observa que el elenco de garantías mínimas establecido en el numeral 2 del artículo 8 de la Convención se aplica a los órdenes mencionados en el numeral 1 del mismo artículo, o sea, la determinación de derechos y obligaciones de orden "civil, laboral, fiscal o de cualquier otro carácter". Esto revela el amplio alcance del debido proceso; el individuo tiene el derecho al debido proceso entendido en los términos del artículo 8.1 y 8.2, tanto en materia penal como en todos estos otros órdenes.

42 Apartado 127.

43 SAGÜÉs, Néstor Pedro (2009) “El procedimiento administrativo. Perspectivas constitucionales” en: Procedimiento y justicia administrativa en América Latina. Ed. Konrad-Adenauer-Stiftung e V., México, [en línea], disponible en: http://www.kas.de/wf/doc/kas_17833-544-4-30.pdf.

${ }^{44}$ Apartado 62. Caso Comunidad indígena Yakye Axa vs. República del Paraguay. Sentencia Corte IDH de $17 \mathrm{de}$ junio de 2005 , Serie C, No. 125.

45

En el presente caso la autoridad estatal administrativa encargada de resolver la solicitud de información no adoptó una decisión escrita debidamente fundamentada, que pudiera permitir conocer cuáles fueron los motivos y normas en que se basó para no entregar parte de la información en el caso concreto y determinar si tal restricción era compatible con los parámetros dispuestos en la Convención, con lo cual dicha decisión fue arbitraria y no cumplió con la garantía de encontrarse debidamente fundamentada protegida en el artículo 8.1 de la Convención.

${ }^{46}$ Comunidad indígena Yakye Axa vs. República del Paraguay. Sentencia Corte IDH de 17 de junio de 2005, Serie C, No. 125 . 
demora, en consecuencia, el Tribunal laconsidera desproporcionada frente a la atención de la Comunidad Yakye una vez que fue desplazada de su lugar de origen.

Cumplir con el plazo previsto para resolver, dar audiencia en el procedimiento así como motivar adecuadamente las resoluciones son proyecciones de la adecuada actividad procedimental administrativa por medio de la cual se ponderan los intereses que confluyen a ésta. Una adecuada sistematización a la luz de la buena administración como principio rector de la actividad administrativa confluye, necesariamente en la protección de los derechos humanos que se materializan a partir de la actividad procedimental. Se trata, en definitiva, de dos perspectivas de un mismo fenómeno, protección del derecho de petición como derecho humano y protección de los derechos humanos que se atienden por medio del procedimiento.

\section{Conclusiones}

Las aportaciones de la gobernanza a la ciencia de la administración como modelo de gestión pública, resultan trascendentales para la construcción del derecho administrativo del siglo XXI. Ésta puede significar un área de oportunidad para eliminar normas que contemplen amplias facultades y prerrogativas injustificadas previstas en el ordenamiento jurídico de las administraciones públicas mexicanas. Incluso consolida una perspectiva integradora, cooperativa y consciente de las necesidades de los ciudadanos en la dinámica de la gestión de los asuntos públicos y la protección del interés general.

En su momento fue la aportación de los estudios realizados por organismos internacionales sobre la gobernanza, los que propusieron un cambio de paradigma en los modelos de gestión púbica y abrió la discusión a formas de trabajo abiertas e incluyentes para las muy variadas áreas en las que pudiera tener injerencia el Estado. En esta medida el trabajo de investigación permitió observar la trascendencia que tiene la gobernanza en el derecho administrativo en el marco de la buena administración, pues supone la consideración del ciudadano en cada una de sus actividades, el fortalecimiento de los principios de eficiencia y eficacia como elementos intrínsecos a la calidad en el quehacer cotidiano de las administraciones públicas.

La buena administración supone una excelente herramienta para la regulación de la actuación administrativa siempre y cuando se reconozca como un derecho fundamental en algún instrumento formal, nacional o internacional (al que México esté suscrito). Además, significaría una garantía de protección y exigibilidad para el ciudadano contra la inactividad procedimental, que le permita contrarrestar en gran medidalas irregularidades en el procedimiento contra las arbitrariedades cometidas por la administración pública.

La posible regulación de la inactividad de las administraciones públicas en los procedimientos administrativos en México, dígase silencio administrativo, fomentan la mala práctica de la administración al permitírsele incumplir con el deber de actuar consagrado en el artículo 8 constitucional. Esta situación exigiría un esfuerzo por parte del legislador para construir sistemas jurídicos sin contradicciones y congruentes. En el derecho administrativo el procedimiento representa la única vía de comunicación con el ciudadano, de ahí que la consideración hacia los criterios que establece la gobernanza y su configuración jurídica a través de la buena administración resulten imprescindibles, pues suponen la protección de derechos humanos materializados a partir de la actividad procedimental ya sea el derecho de petición para el caso de la inactividad administrativa formal como para cualquier otro derecho humano que tenga lugar en el procedimiento.

Los efectos de la gobernanza en el ordenamiento jurídico implican también contribuir en el fortalecimiento de un Estado de derecho y de forma más incisiva en el control de la inactividad 
administrativa. Si consideramos las propuestas planteadas por organismos internacionales observamos que las principales deficiencias que tienen las administraciones públicas en México se deben, en parte, a la falta de mecanismos de comunicación eficientes con los ciudadanos y a la insistencia (por parte del legislador y de la administración) a mantener la batuta de un poder totalitario y subjetivo con un apego formal a la legalidad pero materialmente ejerciendo privilegios que no se justifican ni entienden en el contexto de un mundo globalizado que pone en primer plano como objetivo político y legislativo la protección de los derechos humanos.

\section{Bibliografía}

Aguilar Villanueva, Luis (2014), "De la gobernabilidad a la gobernanza”, Examen, México, año XXIII, Núm. 234, septiembre. (2008), Gobernanza y gestión pública, México, Fondo de Cultura Económica.

(2007), "El aporte de la política pública y de la nueva gestión Pública a la gobernanza”, Revista del Centro Latinoamericano de Administración para el Desarrollo, Reforma y Democracia, Caracas, Núm. 39, Octubre.

Alli-Aranguren, Juan Cruz (2004), “Derecho administrativo y globalización”, Madrid, Civitas.

Amilivia González, Mario y Nalda García, José C. (2008), "Principios de buena administración y función consultiva”, Revista Española de la Función Consultiva, No. 9.

Arenilla Sáez, Manuel (2010), “Administración pública y ciencia de la administración”, en: Arenilla Sáez, Manuel (coord.), La administración pública entre dos siglos: (Ciencia de la Administración, Ciencia Política y Derecho Administrativo): Homenaje a Mariano Baena del Alcázar, España, INAP.

Auby, Jean Bernard (2001), “Globalización y descentralización”, Revista de Administración Pública, No. 156, INAP, Madrid.

Barros Valero, Javier, (2009), “América Latina y México. Administración pública y gobernanza", Revista de Administración Pública, México, vol. XLIV, núm. 3, septiembre-diciembre.

Brito, Mariano (2002), "Globalización y Derecho Administrativo”, Ius Publicum, España, Núm. 9.

Carbonell, Miguel (2012), "Las obligaciones del Estado en el artículo $1^{\circ}$ de la Constitución mexicana", en: La reforma constitucional de derechos humanos. Un nuevo paradigma, Carbonell, M. y Salazar, P. (coords.), Porrúa-UNAM, México.

Closa Montero, Carlos (2003), "El libro Blanco sobre la gobernanza", Revista de Estudios Políticos, España, Núm. 119. 
Domínguez URibe, Alejandro, "La gobernanza y sus implicaciones” en: Pérez F. G. y González U. P (coords.) Tendencias actuales de la ciencia política. Temas de análisis para comprender un mundo en cambio, Tomo II, UNAM, México.

Fernández GonzÁlez, Miguel Angel (2012), “Globalización: Rol de derecho público y transformación del Estado”, Revista chilena de derecho, Chile, Núm. 187.

Ferrajoli, Luigi (2016), "Sobre los Derechos Fundamentales", Cuestiones Constitucionales Revista Mexicana de Derecho Constitucional, Trad. Miguel Carbonell, núm. 15, UNAM, julio-diciembre.

García De Enterría, Eduardo (2009), Democracia, jueces y control de la Administración, VI edición, Cizur Menor, Aranzadi.

(2004), La Revolución Francesa y Administración contemporánea, Madrid,

Civitas.

García SAnchez, Isabel (2007), La nueva gerencia pública: evolución y tendencias, Presupuesto y gasto público, España, Vol. 47.

GonzÁlez Alonso, Luis N. (2008), "Derecho a una buena administración" en: Carta de los derechos fundamentales de la Unión Europea: Comentario artículo por artículo, Fundación BBVA, Madrid.

Luciano Parejo, Alfonso (1995), Eficacia y administración, Madrid, Ministerio para las Administraciones Públicas, INAP y Ministerio de La Presidencia.

Nieto García, Alejandro (2008), El desgobierno de lo público, Ariel.

(2001), Estudios de derecho y ciencia de la administración, Madrid, Centro de Estudios Políticos y Constitucionales.

Ponce Solé, Julie (2012), "Buena administración”, Diccionario de Derechos Humanos, Universidad de Alcalá, [en línea], disponible en: http://diccionario.pradpi.org/inicio/index.php/ terminos_pub/to_pdf/4o.

(2008), "Desarrollo territorial sostenible y buena administración mediante la actividad de planificación en la Ley 8/2007, de 28 de mayo, de suelo" en: El derecho urbanístico del siglo XXI: Libro homenaje a Martín Bassols Coma, Editorial Reus.

(2001), El deber de buena administración y el derecho al procedimiento administrativo debido. Las bases constitucionales del procedimiento administrativo $y$ del ejercicio de la discrecionalidad, Valladolid, Lex Nova.

Rodríguez Arana, Jaime (2013), "La buena administración como principio y como derecho fundamental en Europa", Misión Jurídica, Bogotá Colombia, núm. 6, enero-diciembre 2013. 
(2011), "El principio a la buena administración como derecho estatutario, competencia y objetivo de los poderes públicos autonómicos” en: Ávila Carmen y Gutiérrez Francisco (Coords.), El derecho a una buena administración y la ética pública, Valencia, Fundación General de la Universidad de Málaga.

Rodríguez Pontón, Francisco José (2010), “La articulación de las garantías administrativas y jurisdiccionales en el sistema del CEDH", Thomson-Civitas, Cizur Menor, 2005. In totum Parisio, Vera, (dir.) Diritti interni, diritto comunitario e principi sovranazionali,Giuffè, Milán.

SAGÜÉs, Néstor Pedro (2009), "El procedimiento administrativo. Perspectivas constitucionales" en: Procedimiento y justicia administrativa en América Latina. Ed. Konrad-AdenauerStiftung e V., México, [en línea], disponible en: http://www.kas.de/wf/doc/kas_17833-5444-30.pdf.

SÁnchez Blanco, Ángel (2008), "De la actividad archivística como función pública y de su incidencia en los derechos de los ciudadanos y en la buena administración”, Revista General de Derecho Administrativo, No. 17.

SÁnchez GonzÁlez, José (2002), Gestión pública y governance, México, Instituto de Administración Pública del Estado de México.

Sánchez Morón, Miguel (2008), Derecho Administrativo, Parte general, $4^{\circ}$ ed. Tecnos, Madrid.

Serna De La Garza, José María (2010), Globalización y gobernanza: las transformaciones del estado y sus implicaciones para el derecho público: contribución para una interpretación del caso de la guardería ABC, México, UNAM-Instituto de Investigaciones Jurídicas.

SolÀ, Amadeu (200o), "La traducción de gobernanza”, Punto y Coma, núm. 65, septiembre-octubre, [en línea], disponible en: http://ec.europa.eu/translation/bulletins/puntoycoma/65/ pyc652.htm.

WitKer, Jorge (2015), "El derecho económico y los derechos sociales en la gobernanza actual" en: Carbonell Miguel y Cruz Oscar (Coords.), Historia y Constitución. Homenaje a José Luis Soberanes Fernández, México, UNAM- IIJUNAM, 2015, t. I.

\section{Documentos internacionales:}

OECD, Governance in Transition. Public Management reforms in Countries, París, 1995.

UNDP, Reconceptualising Governance, Discusión paper núm 2, Management Development and Governance, División, Bureau for Policy and Programme Support, UNDP, Nueva York, enero de 1997, p.9.

Cumplir con la promesa: unidos para lograr los Objetivos de Desarrollo del Milenio, suscrito en Nueva York el 19 de octubre de 2010.

La Declaración del Milenio, Nueva York, 13 de septiembre del 2000. 


\section{Legislación:}

Ley Federal de Procedimiento Administrativo

Proyecto de Constitución Política de la Ciudad de México, presentada el 15 de septiembre de 2016, [en línea], disponible en: http://gaceta.diputados.gob.mx/ACCM/DOC/ProyectoConst15sep.pdf.

Constitución Política de la Ciudad de México, publicada el 5 de febrero de 2017, [en línea], disponible en: http://www.cdmx.gob.mx/storage/app/uploads/public/589/746/ ef5/589746ef5f8cc447475176.pdf.

Constitución política de los Estados Unidos Mexicanos.

Corte interamericana de Derechos Humanos.

Convención de Derechos Humanos y Libertades Fundamentales

Carta de los Derechos Fundamentales de la Unión Europea

Convención Americana sobre Derechos Humanos.

El Protocolo de San Salvador.

\section{Jurisprudencia}

Baena Ricardo. Sentencia Corte IDH de 2 de febrero de 2001. Serie C No. 72.

Claude Reyes y otros vs. Chile. Sentencia Corte IDH de 19 de septiembre de 2006, Serie C No. 151.

Comunidad indígena Yakye Axa vs. República del Paraguay. Sentencia Corte IDH de 17 de junio de 2005, Serie C, No. 125. 